\title{
An Empirical Investigation into Organization Culture and Size Impact on Marketing Concept Implementation
}

\author{
${ }^{1}$ Slah H Amhemad and ${ }^{2}$ Zurina Shafii \\ ${ }^{1}$ Faculty of Economics and Muamalat, Universiti Sains Islam Malaysia, 71800, Nilai, Negeri Sembilan, \\ Malaysia, \\ ${ }^{2}$ Associate Professor, Faculty of Economics and Muamalat \& Director, Islamic Finance and Wealth anagement \\ Institute, Universiti Sains Islam Malaysia, 71800, Nilai, Negeri Sembilan, Malaysia.
}

\begin{abstract}
The concept of marketing is going throughout the orientation is providing the organization a much better understanding for their competitors, customers and practices of business. This paper is exploring the relationship between the business performance and the market orientation in the variety of small sized banking organizations. The major focus of this study is to explore the concept of marketing in the small sized banking organizations. This study is also examining the level of the orientation in the market with the relationship of organization culture and its size.
\end{abstract}

\section{1}

Background

\section{Introduction}

There is the general argument that suggested that a marketer should pay much more attention towards the needs and wants of their customers in order to achieve the strong relationship with them. The marketing concepts are considered as the most fundamental approach that defines the philosophy of marketing to achieve the goal of the organization. It is mainly depending on the target market needs and wants and delivers them only those products that full fill their desire needs in most efficient manner as compare with competitors.

The small and medium sized banking organizations are generally facing the fierce competition all around the world due to globalization and existence of Multinational Corporation in the local market. Concept of marketing is one of the tenants in the field of marketing that widely consist over the three crucial elements; orientation of customer, wide efforts from organization to achieve goal related with customer, and an integrated approach.

McCarthy \& Perreault [1] suggested that the organization is implementing the concept of marketing also adopted as the orientation of marketing. Orientation of marketing is the key element that refereed as the key and important strategy of marketing. Marketing concept includes the services and orientation that has been studied to developed the framework of marketing concept, and it is also supported that the making concepts is highly correlated with the performance of the organization.

Although this is suggested that the importance of marketing concepts in the banking organization, the purpose of this study is to examine the organizational culture and size influence on the Marketing concept implementation with investigating the small and medium sized banking organization.

\subsection{Problem Statement}

Although this is much clear that Marketing concept is the well established term in knowledge of marketing, there is little guidance that helping to make it implementation in an organization. There are few activities of marketing concepts that need to translate in philosophy in order to make it implementation thus it's not clear. According to marketing scholar the Marketing concept does required the momentary attention although it has been establishing the important element in the organization that influence it performance. This is also considered as the weighty issues and still unresolved in literature of marketing to manage Marketing concept in small and medium size banking organizations.

\subsection{Significance of the Study}

This study is significant in both practical and theoretical backgrounds. The study is also examined the marketing concept, principle of foundation in the influence of internal variable. As the competition is become quite strong in diverse industries does the role of marketing have now become much critical for the organization success.

This study is suggesting that factors that influence in the Marketing concepts implementation in small and medium size banking organizations. According to (Kohli et.al, [2] market orientation antecedents and the marketing organization effect on the firm profitability. Practices of marketing do simply accept that Marking concept as marketing gospel with require few attention and guidelines that help and facilitating its implementation. 
From the experiential perspective, this is study has an aim to suggested the evidence of the managerial implication that utilizing when the organization of the small scale industry that attempt to developed and implement the marketing orientation or marketing concept. For example, the culture of the organization is identifying the relationship of marketing with the orientation marketing, and we can use this information to formulating the most effective strategies with the regards of cultural organization.

Finally, the research the sustainability and development of marketing orientation in the small scale industry by the introduction of Marketing concepts so they are capable of creating the values of superior customer and maintain better competitive advantage in the market.

\section{$1.4 \quad$ Objective of Study}

The objective of this study is the investigation was to study the organizing size influence and culture on the marketing implementation concepts from the perspective of the small and medium size banking organizations. The study is also sought to testing the hypothesis empirically with regard on antecedents on the market orientation. The study will examine to accomplish the specific goals.

1. Exploring the marketing concept in the small and medium sized banking organizations and also examine the marketing concept level with the term of culture and size of organization.

2. Investigating the relation between the influence of organization size and culture on market orientation.

The area that we choose for this research is small and medium sized banking organization that requires a separate attention. These organizations are generally required the efforts of integrated marketing and market orientation commitment to successfully implementing the concepts of marketing.

\subsection{Research Questions}

This study is asked the three crucial questions that addressing the Marketing concepts in the business of small and medium sized banking organizations. The questions for this study were as followed

1. Do organizational culture facets and orientation survey (OCO) impact on number of employees predicting the marketing orientation?

2. Do organizational culture facets and orientation survey (OCO) impact on number of employees predicting the iterfunctional orientation?

3. Do organizational culture facets and orientation survey (OCO) impact on number of employees predicting the competitor orientation?

\subsection{Justification of the Study}

This study is investigated the small and medium sized banking organizations that routinely facing the fierce competition due to the existence of large and multinational corporation in their domestic market. As the result, this organization would be much dependent on the approach of integrated marketing including the Marketing concept, service orientation and the market orientating. According to Cooper \& Schindler, [3] the successful management does require considering that the organizational influence on the organizational culture and size in the marketing concept implementation.

Marketing orientation is one of severe technique of marketing concepts that engaged in to deal with the great attention from the scholars of marketing. Blankson \& Cheng, [4] investigated their research on the market orientation in the small business sectors, attention of policy makers and the orientation, academics and practitioners. This is not a surprise evaluation that the small and medium sized banking organizations are considered to bet eh engine on the particular economy. This study is also added the literature on the market orientation interface and small size business.

\subsection{Limitation of the Study}

The finding of this study does not generalization for all banking organizations. This study is only focusing the small and medium size banking organization, and finding may not generalize the larger banking organizations. Due to limited financial resources for this research, the result obtained through a few sample size of only limited geographical area of Libyan Banking Organisations, so it is not generalized study for constant sample size. Availability of timeframe was another limitation in this study.

\section{Literature}

The literature review of this paper is providing the theoretical background that use to facilitate the concept understanding the relationship that examined with the study. The first part is describing the concept of marketing that includes the orientation of market. This was also considered that contribution for the market orientation. The organizational culture is also reviews on relationships and concepts of the marketing concept and the culture of the organization. 
In year 1950, the Marketing Concept has become the turning point, and this was the time that the Marketing concept has grown the status and popularity. According to Kotler, [5] the organizational key success is the goal that consisting on determining the need of their respective target market in more effective and more efficient way that satisfy their needs as it is compare with organization competitors. This was previously defined that the marketing concept is considered as the corporate state of mind that insisting over the integration and the marketing function coordination for the basic purpose to provide the longer range of organization profit. There is the need to build the marketing concept philosophy in the entire organization culture in order to achieve the success of business marketing.

According to Kotler, [6] there are four major pillars on which Marking concepts were based; (a) focus of target market (b) customer orientation (c) marketing coordination (d) organization profitability. This concept is basically quite different from the concept of selling that was taking inside perspective starts from the level of production and focusing on heavy promotional activity to increase sales and profit of the business. On the other hand, Marketing Concepts is also taking the internal perspectives that starting from the market that is defines and needs of customers, coordinating the activities that affecting directly towards customers and engaged in producing of profit by satisfying needs of customers.

The adaption of the Marketing Concept on the smaller size organization is based on the implementation of it. Smaller organization is likely to larger counterparts that guided all over the firm philosophies as should be doing next. One key philosophy of the Marketing concepts was an operational approach that provides the overall perspectives of the organizational members.

Peterson [7] found that the smaller business have been lesser inclined to the embraces of Marketing concepts. The study is assessing the small business directors. The studying was covering the difficulties to assessing the adoption and Marketing Concept implementation. The manager was asked to the measuring their agreement with the statement that thought every single person embodies the basic needs. They were asked about the production, sales, marketing concepts philosophies were based on the most accurate way in the business. They were also asked about their business nature. Finding suggests that the Marketing concept is becoming part of the basic philosophy on the various business organizations. While on the other hand, the larger number of manager's states that they were embracing the production and sales philosophy. The study was also demonstrated that the in the bulk of small size business Marketing concept more towards in the retailing side. First related with services does not embrace frequent Marking concepts in a large number.

Moorman \& Rust [8] was found that the Marketing concept adoption by the smaller firms become the more reluctant as it compare with the larger firms in order to embracing the goal of the organization. This is because they are not believed that marketing concepts does not realm their goals. Many of them are non profit, but they are existing for a reason that involves ownership pride, independence and achievement sense. On the other side, number of organizations also pursue this concept in order to determine that this will helpful to achieve firms objects where the philosophies does remain failed.

According to Narver \& Slater [9], the culture of organization that creates in most effective and efficient manner does create the supervision of their values and enjoying their organization continues improvement. They also describe these concepts based on three components that include interfunctional coordination, customer orientation and competitor orientation.

\section{Methodology}

It is a critical component of any research that provides a road map for how the study will proceed and how study questioners will be answered. Section of methodology is including information related with subject, sample size and research instrument for collecting data.

\subsection{Research Design}

The research design can be thought as the structure of competent. Research design is commonly used to summarize the typical design in a competent manager. There are generally three major types of research design that could be used for the research to carry out: quantitative, qualitative and mixed research methodology.

This research was use quantitative research approach. Quantitative research design allows the researcher to use different statistical test to examine the proposed research aim. Under quantitative research design the research data set is quantifiable and analyzed by using statistics. This research helps to investigate the valuable information, such as uncovering the leading reasons of physical behavior in small and medium sized business.

\subsection{Research Purpose}

The exploratory research has been used for this research which is help full to gather preliminary information to define the real problem. Questionnaire is used as a research instrument where the data required is quantifiable. The researcher uses the questionnaire form to collect data which is quantitative in nature. The questionnaire can be a major part of this research success. 


\subsection{Data Source}

Data was collected from taken through the questionnaires from 5 participants presenting in the small and medium size banking organizations. The existence of their business is from between 1 and 40 years. Business has the employees between 4 and 300 with a mean of 60 employees. Participant of the study were also asked to provide the information over the type of the employees working in their bank. Types of employees included, engineers, production managers, sales and marketing employees. Additionally participant were also asked that whether they listened to the need and wants of their different customers.

\subsection{Target Population}

Target population for this research was the small and medium sized organizations in the banking industry.

\subsection{Sample Size}

For this research, there are 5 banks are choose to collect data.

\subsection{Sampling Technique}

Purposive (non-probability) sampling technique is used for this research; sample is based on those peoples who are supposed to be appropriate for the study because there are limited people that have expertise in that particular field.

\section{Data Analysis}

All data received from the questionnaire survey was coded and entered into SPSS for analysis. Reliability tests(Cronbach Coefficient alphas) were performed on all measurement instruments.

\subsection{Results of the Study}

\subsubsection{Demographic Profile of Respondents:}

As illustrated in Figure 1, there was a bigger percentage of male respondents $(81.6 \%)$ than female respondents $(18.4 \%)$. The majority of respondents were have bachelor degree $(52.3 \%)$, followed by higher diploma(26.1\%), and intermediate diploma (14.8). Figure 2 shows the education level of the respondents.

Figure 1 Gender of Respondents

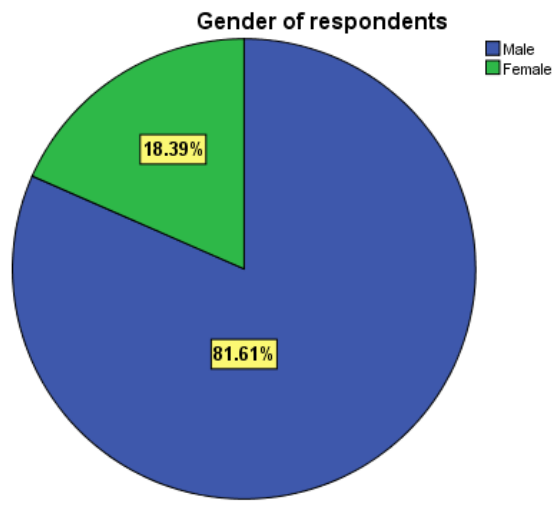

Figure 2 Education Level of Respondents

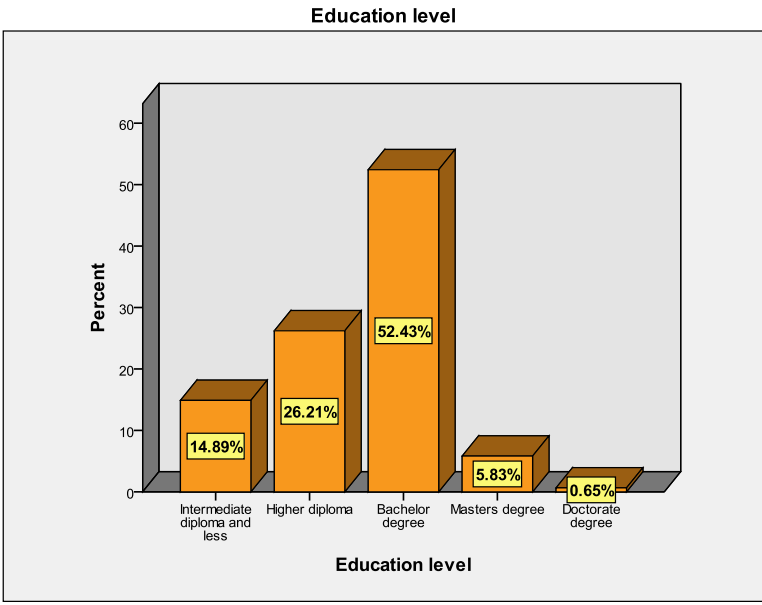




\subsubsection{Bank' Profile:}

\section{* Number of Employees}

As illustrated in Figure 3 There were 65.2 percent of the respondents who have taken part in this research study, their banks have 1-50 employees. There were 24.2 percent of the respondents who have taken part in this research study, their banks have 51-200 employees. There were only 10.6 percent of the respondents who have taken part in this research study, their banks have more than 200 employees. So it can be said that most of the banks have 1-50 employees.

Figure 3: Distribution of the Respondents by Number of Employees

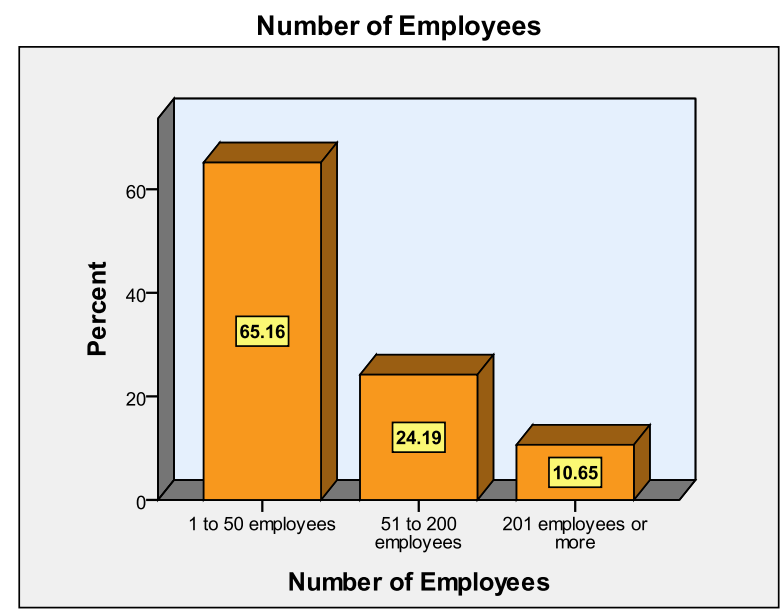

\section{* Type of Business}

Respondents were asked to classify the type of' activity/business in their banks by being presented with two sub-groups, which are carefully selected to represent the type of business for the Libyan banks. Table 1 shows the type of businesses and their frequencies. The table shows that the majority of respondents' bank were from commercial sub-group banks at about 77 per cent (124) whereas only about 23 per cent (39) were from specialized sub-group banks.

Table 1: Type of Business Classification

\begin{tabular}{|c|c|c|}
\hline Type of Business & Frequency & Valid Percent \\
\hline Commercial & 124 & 76.9 \\
\hline Specialized & 39 & 23.1 \\
\hline Total & 163 & 100 \\
\hline
\end{tabular}

\section{* The Total of Assets}

The size of the bank in which the banks can be split into two sub-groups which are small and large sub-groups based on the total of assets, banks with less than 100 million LD are classified as small whereas banks with 100 million LD or more are classified as large. In this context, table 2 shows that about 39 per cent (64) of responding banks had less than 100 million Libyan dinar (LD) as total of assets. By contrast, 27.6 per cent (45) of banks have between 100 to $500 \mathrm{LD}$ million as total assets, it also shows that with more than 33.1 per cent (54) have in excess of 500 DL million assets.

\begin{tabular}{|l|l|c|c|}
\hline & Total of Assets (LD) & Frequency & \multicolumn{2}{l|}{ Valid Percent } \\
\hline \multirow{2}{*}{ Small } & 100 Million < & 64 & 39.3 \\
\hline \multirow{2}{*}{ Large } & $100-500$ Million & 45 & 27.6 \\
\cline { 2 - 4 } & 500 Million > Total & 54 & 33.1 \\
\hline
\end{tabular}

\subsection{Relaibilty Analyses}

Cronbach alpha reliability tests were performed on all scales. Table 3 presents the reliability coefficients of all the psychometric scales used in this study. The reliability coefficients of 0.70 and above were generally found to be internally consistent Nunnally,[10]. The orientation of market and customer marketing orientation were found to have high reliability scores of over 0.90 . 
Table 3 Reliability Coefficients

\begin{tabular}{|l|c|}
\hline \multicolumn{1}{|c|}{ Variables } & Cronbach Alpha \\
\hline Orientation of Market & 0.91 \\
\hline Interfunctional Coordination & 0.70 \\
\hline Customer Orientation & 0.92 \\
\hline Organization Culture & 0.82 \\
\hline
\end{tabular}

\subsection{Correlation Analysis}

The table 4 presents the findings of correlation analysis among the market oriention, interfunctional coordination, customer orientation, and organization culture. The value of Pearson correlation among market oriention and interfunctional coordination is $0.069(\mathrm{r}=0.069, \mathrm{p}=0.111<0.05)$, which indicates that there exists a positive relationship among these two variables. The change in one variable may somewhat affect the other variable. The value of Pearson correlation among market oriention and Customer Orientation is $0.118(\mathrm{r}=$ $0.118, \mathrm{p}=0.019<0.05$ ), which indicates that there exists a positive relationship among these two variables. The change in one variable may somewhat affect the other variable. The value of Pearson correlation among market oriention and Organization Culture is $0.223(\mathrm{r}=0.223, \mathrm{p}=0.000<0.05)$, which indicates that there exists a positive relationship among these two variables. The change in one variable may somewhat affect the other variable.

Table 4 Correlation Matrix for the variables

\begin{tabular}{|c|c|c|c|c|c|}
\hline Items & Analytical Techniques & Y-Mo & IC & $\mathrm{CO}$ & OC \\
\hline \multirow[t]{2}{*}{ Y-Mo } & Pearson correlation & 1.00 & & & \\
\hline & Sig & & & & \\
\hline \multirow[t]{2}{*}{ IC } & Pearson correlation & 0.069 & 1.00 & & \\
\hline & Sig & 0.111 & & & \\
\hline \multirow[t]{2}{*}{$\mathrm{CO}$} & Pearson correlation & 0.118 & -.117 & 1.00 & \\
\hline & Sig & 0.019 & .040 & & \\
\hline \multirow[t]{2}{*}{ OC } & Pearson correlation & 0.223 & .098 & .241 & 1.00 \\
\hline & Sig & 0.000 & .085 & .000 & \\
\hline
\end{tabular}

\subsection{Discussion}

This study was set to describe the business participants from the small and medium size banking organizations. The majority of these banks are engaged to collect the on their competitors and customers are working diligently to fulfill the immediate needs and wants of their customers. The items of marketing such OCO were also found as the variable reliable that subscribes within the items of marketing. The study was successful identifies that the different sets of the predicted variable for the orientation of the market such as customer, competitors and interfunctional that indicating that small and the medium size business have the different perception about that influencing the orientation of market.

Customer marketing orientation that enables the organization to monitor and understand about the perception that needs the target market and they are continuously creating the customer values. The analysis shows all the facets under the importance of business in the culture of organization subscale have directly affect over how they monitor the perception of their target market customers. The small and medium sized banking organizations are fiercely facing tough competition due to the existence of Multinational Corporation. The competition in the market is intensifies, orientation, advocacy, marketing philosophy and practices throughout the organization seem to the phenomenal success for any organization in this competitive environment.

It was also investigated that type of business and the number of employees in the banking organization have a significant impact over the small and medium size banking organization. Orientation of market from the perspective of competition allows this organization to monitor the information of competitor and easily share within their organization. From the part of subscale of organization culture, there is a significant influence of market culture over orientation of market.

Culture of market foster the system values that facilitating the information sharing and meaning that uphold the importance through coordinated efforts and marketing intelligence usage to achieve market place effectiveness.

Market orientations iterfunctional involves the coordination resources of the organization to create the customer value superiority. The above three variables predicting in such way that small and medium sized banking organization coordinate their resources that creating their customer value. The number of employees 
does not predict the market orientation iterfunctional that means the organization size does not influence the marketing orientation. The banking organization does not determine that whether the coordinating activities in such manner that enable the organization to delivering customer value superiority.

The marketing concepts in banking organizations mind does insisting the integration and coordinating with all functions of marketing for the purpose of produce the longer range of bank profit. The marketing concept philosophy must have to build the culture for the entire banking organization as the success of marketing beginning. The concept does not define the factor of size on its implementation.

\subsection{Conclusion}

\section{Conclusion and Recommendations}

The finding of this research is suggested that the orientation of market in the smaller and medium sized banking organization is unquestionably influencing by the organizational culture and its size. Organizational culture is defining the share values patter, and it beliefs that helping the individual to understand the organizational functioning provides with normal behavior in the firm. This is investigating the manager perception implement and develops the concept of marketing by consideration organization culture and size.

\subsection{Recommendations}

Small and medium sized banking organizations are require to pay attention in order to increase the coordination level of iterfunctional due to market orientating has seen the significant effect over performance of the organization. As the organization functions should coordinate in such way that gaining the concept of marketing that derived in order to crating the superior value of customer.

As the result of this study, there are would greatly improving the implementation and adoption of the marketing concept. This would also helps the manager to implement the concept for appreciate this concept as the key role in organization performance.

Smaller scale organization are required to engage in the better prices of products, better delivery times and improves the customer values than their rivals Deshpande \& Parasuraman,[11]. Marketing concepts helps the managers to coordinate and plan all activities to achieve the desire results. Marketing is incorporating the cultural differentiate in the tendency to provide the better customer values, it is become possible to predicting the customer preferences that more precisely and presenting the changes for the market place.

\subsection{Future Research}

There has been little research done in this filed. However, this study addressed the gap existed. The more research will be required to carry out for boosting the knowledge of small and medium sized organization of Marketing Concept.

\section{Reference}

[1]. McCarthy, E., \& Perreault, W. (1984). Basic marketing. Homewood, IL: Irwin, retrieved from: http://faculty.mercer.edu/jackson_r/Ownership/chap19.pdf.

[2]. Kohli, A. J., Jaworski, B., \& Kumar, A. (1993). MARKOR: A measure of market orientation. Journal of Marketing Research, 30, 467477, retrieved from: http://www.jstor.org/discover/10.2307/3172691?uid=3738832\&uid=2\&uid=4\&sid=21101830649403.

[3]. Cooper, R, D., \& Schindler, P. S. (2003). Business research methods (9th ed). Boston: McGraw-Hill Irwin, retrieved from: http://www.cengagebrain.co.nz/content/9781285202082.pdf

[4]. Blankson, C., \& Cheng, J. M. (2005). Have small businesses adopted the market orientation concept? The case of small businesses in Michigan. Journal of Business and Industrial Marketing, 20, 317, retrieved from: http://ebookbrowse.com/have-small-businessesadopted-the-market-orientation-concept-pdf-d69129433

[5]. Kotler, P. (1984). Marketing management (5th ed). Englewood Cliffs, NJ: Prentice- Hall, retrieved from: http://dl.is.vnu.edu.vn/dspace/bitstream/123456789/250/1/Global_Marketing_management.pdf

[6]. Kotler, P. (1991). Marketing management: Analysis, planning, implementation and control. Englewood Cliffs, NJ: Prentice- Hall, retrieved from: http://www.epiheirimatikotita.gr/900B03A2-3CDF-41EF-91C3-98B1A3190AE4/FinalDownload/DownloadIdBFE24BB7197A0DA312801A2836D06F7B/900B03A2-3CDF-41EF-91C3-

98B1A3190AE4/elibrary/marketingsales/Philip\%20Kotler\%20-

\%20Marketing\%20Management\%20(Prentice\%20Hall\%20Ptr,\%202002)\%20Fixed.pdf.

[7]. Peterson, R. T. (1989). Small business adoption of the marketing concept vs. other business strategies. Journal of Small Business Management, 27(1), 38, retrieved from: http://www.questia.com/library/1G1-7447669/small-business-adoption-of-the-marketingconcept-vs

[8]. Moorman, C., \& Rust, R. T. (1990). The role of marketing. Journal of Marketing, 63, 180-197, retrieved from: http://www.rhsmith.umd.edu/marketing/pdfs_docs/Article\%20Rust\%20JM\%201999.pdf

[9]. Narver, J., \& Slater, S. (1993). Market orientation and customer service: The implications for business performance. European Advances in Consumer Research. 1, 317-321, retrieved from: http://marketing-bulletin.massey.ac.nz/V13/MB_V13_A3_Farrell.pdf.

[10]. Nunnally, J. 1978. Psychometric Theory. New York: Mc Graw Hill.

[11]. Deshpande, R., \& Parasuraman, A. (1986). Linking corporate culture to strategic planning. Business Horizons, 29, 28-37, retrieved from: http://www.methodframeworks.com/blog/2011/corporate-culture-pressing-reset-button/index.html. 